\title{
Occupational and Non-occupational Stress Among Teachers Depending on the School Type
}

\author{
Agata Szyjkowska \\ Nofer Institute of Occupational Medicine
}

\begin{abstract}
:
Occupational and Non-Occupational Stress Among Teachers Depending on the School Type.The aim of the project was to assess the level of general and professional stress among teachers depending on the school type. In order to assess the level of general stress, the Perceived Stress Scale (according to Cohen) was applied. The occupational stress was assessed using the Subjective Job Assessment Questionnaire. Out of 650 distributed questionnaires, $64 \%$ were returned. The average age of the respondents was $47.6 \pm 8.2$ and work experience - 21.6 \pm 9.2 (0.5-43 years). In the studied group, general stress was at an average level of 25.5 \pm 7.6 (3-53 points) and was significantly higher among high school teachers compared to teachers from primary, technical and vocational schools $(28.03 \pm 7.71$, $25.85 \pm 8.0,23.15 \pm 8.25 ; \mathrm{p}=0.012$ ). Significantly more technical secondary school and vocational school teachers, compared to high school teachers, stated that they were never sure of being able to manage their affairs independently (36.0\% vs. $13.2 \%$; $\mathrm{p}=0.002)$. Occupational stress was at a high level and equaled 112.2 \pm 35.1 (65-223 points). Significantly more teachers of special schools (12.9\%) assessed their work as requiring high physical effort ( $\mathrm{p}=0.011$ ) and experienced lack of support and mobbing on the part of their supervisors and colleagues $(30 \% ; \mathrm{p}=0.0001)$. On the other hand, high school teachers significantly more often considered competition among colleagues as an aggravating factor $(32.4 \% ; \mathrm{p}=0.001))$. Also, more of them stated $(23.8 \% ; \mathrm{p}=0.010)$ that they were often bothered at work by the need to perform tasks within deadlines, although serious obstacles prevented meeting the deadlines, and felt treated worse than their colleagues $(21,6 \% ; \mathrm{p}=0,0001)$.
\end{abstract}

Keywords: teachers, stress 